\title{
Estimation Model of the Change in Dairy Leaf Surface Temperature Using Scaling Technique
}

\author{
Ki-Cheol Eom* and Ho-Yong Eom \\ SEjong Institute of Data Analysis (SEIDA), Suwon 443-766, Korea
}

(Received: September 27 2013, Accepted: October 2 2013)

This study was conducted to develop a model to estimate crop leaf surface temperature. The results were as following; A definition for the daily time based on elapsed time from the midnight $(00: 00)$ as $\ulcorner E \& E$ time $\lrcorner$ with the unit of Kmin. was suggested. The model to estimate the scaled temperature $\left(T^{*} \mathrm{e}\right)$ of crop leaf surface temperature by scale factor $\left(T^{*}\right)$ according to the $\left\ulcorner E \& E\right.$ time $:$ Kmin.」 $(X)$ was developed as eq. (1) $T^{*} e=0.5$ $\cdot \sin (X+780)+0.5(2) T^{*}=(T x-T n) /(T m-T n), T x$ : Daily leaf temperature, $\mathbf{T m}$ : Daily maximum leaf temperature, Tn : Daily minimum leaf temperature. Relative sensitivity of the measured temperature compared to the estimated temperature of red pepper, soybean and persimmon was $1.078,1.033$ and 0.973 , respectively.

Key words: Leaf surface temperature, Scaling technique, Relative sensitivity

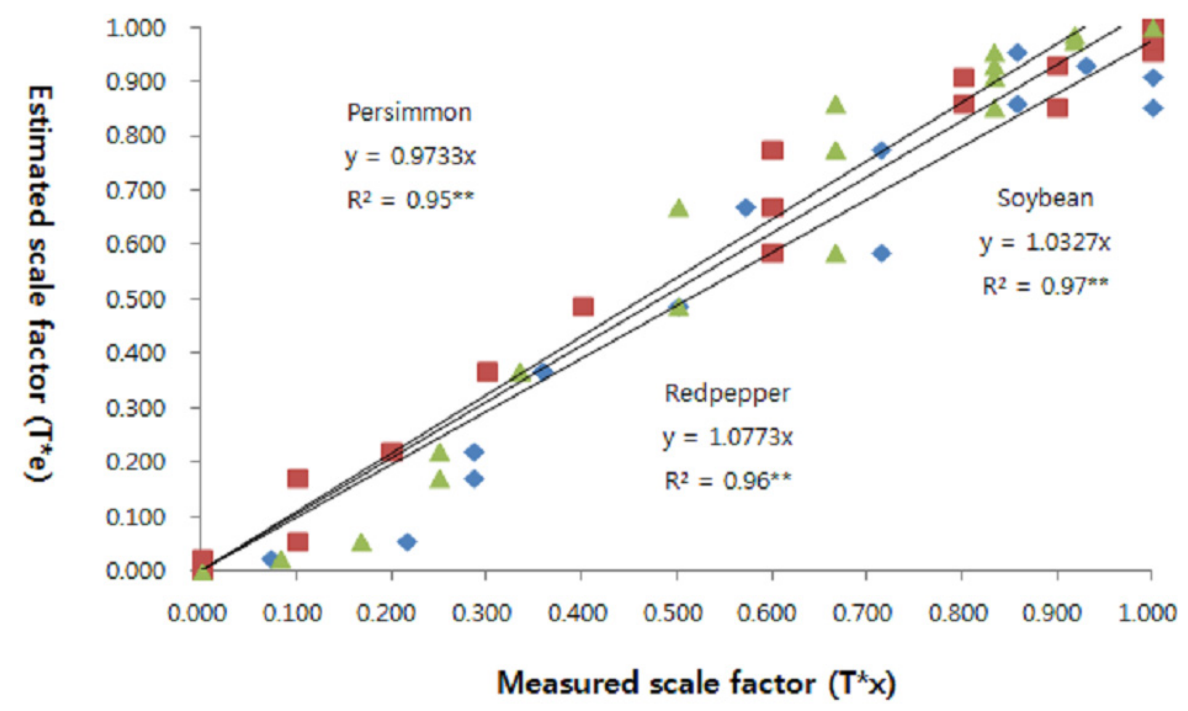

Relationship between the measured and estimated scale factors for the leaf surface temperature. 


\section{Introduction}

작물의 생육 상태를 알기 위하여서는 수분이나 양분의 흡수상태 등 여러 요인을 조사하여야 하지만, 작물체의 온 도는 생육상태와 관련된 하나의 지표 (indicator)가 되기도 한다.

그러나 작물 체내의 온도를 측정하기 위해서는 thermocouple (Scott, 2000 : Lal and Shukla, 2004) 등 고가의 측정기와 고도의 측정 기술이 있어야 하며, 체내 온도와 표면 온도와 는 당연히 상관이 있기 때문에, 작물생리 연구 등에 있어서 비교적 측정이 용이한 작물체의 표면 온도 또한 중요 연구 대상 중의 하나일 것이다. 또한 작물체의 어느 부위에 대하 여 표면온도의 변화 양상을 구명하기 위하여서는 작물의 생 육기간 동안 경시적으로 매일 일정한 시각에 조사를 하여야 할 것이다. 그러나 측정 대상 온도의 일중 변화 양상을 구명 하면 하루 중 시각 별 상대 측정치가 산정 가능하므로 경시 적으로 측정할 경우에도 매일 같은 시각에 측정하지 않아도 될 것이다. 하지만 이에 대한 연구는 매우 미흡한 실정이다. 특히 작물 잎 표면온도의 일중 변화양상을 예측 또는 추정 할 수 있는 모형이 개발되면 작물 관련 연구에 매우 도움이 되리라 생각된다. 물론 현재까지의 modeling과 관련된 많은 연구결과를 활용하면 그 변화양상을 추정할 수도 있겠으나, 이들 모형은 대부분이 외국에서 개발되었으며 워낙 복잡한 이론 도입과 실제 작물 재배 조건과 잘 맞지 않는 가정 하에 서 유도된 수학적인 함수에만 의존하고 있는 것들이 대부분 이어서 그 활용정도는 매우 낮은 실정이다 (Eom et al., 1995).

따라서 활용성 있는 간편한 모형 개발이 요구되는 실정 이다. 이를 위해서는 몇 가지 공시작물에 대하여 연중 그 변 화폭이 가장 큰 시기의 변화양상 구명을 통하여 타 작물 또 는 타 생육기에도 적용 가능한 모형이 개발 되어야 할 필요 성이 있다고 생각된다.

이와같은 모형 개발에 유용하게 활용되는 연구 방법 중 하나가 Scaling technique (Miller and Miller, 1955a, 1955b : Hillel and Erick, 1990 : Eom \& Eom, 2008)일 것이다. 즉, 어떤 조건에서 실측한 온도 data를 이용하여, 다른 경우 의 온도 특성과 가장 관련 있는 변환계수인 scale factor를 구하여 추정 대상 온도 변화에 대한 일반적인 경향을 파악 할 수 있게 해 주는 방법으로서, scale factor를 구하는 방법 에 따라 dimensional 분석법, inspectional 분석법 및 similitude 분석법으로 대별 될 수 있다 (Patricia and Nielsen, 1984 : Eom et al., 1995). 이 중에서 온도 변화와 관련하여서는 어 떤 물체 내에서의 열 이동은 Fourier's law를 따를 것이라는 가정 하에 similitude 분석법에 기초하여 회귀계수 유도에 의한 기법이 가장 활용도가 높다고 할 수 있다 (Patricia and Nielsen, 1984).

뿐만 아니라, 어떤 모형이 개발되어 그 모형에 의한 예측 또는 추정치의 정밀도를 분석하여 실측 시 같은 정밀도를 얻기 위해 요구되는 상대적 반복치의 수를 산정할 수 있는 방법으로는 상대정밀도 (Relative sensitivity : RS) 분석 방 법 (Mandel, 1964 : Eom et al.,1988)이 활용되고 있다.

따라서 본 연구에서는 작물 잎 표면온도에 대하여 similitude 분석법에 기초한 scale factor를 구하여, 일반적으로 활용
가능한 작물 잎 표면 온도의 일중 변화 양상을 추정 할 수 있는 모형을 개발하고, 이 모형을 이용하여 공시 작물 별 같 은 정밀도를 얻기 위해 필요한 상대적 측정 반복수를 산정 비교 분석하고자 하였다.

본 연구는, 금후 물질의 표면온도 관련 연구, 특히 작물 잎 또는 다른 물체의 표면온도 측정 시 경시적 측정이 요구 되는 경우나, 측정 반복치 결정 등에 기여 할 수 있으리라 생각된다.

\section{Materials and Methods}

본 연구는 고추 (품종명:금강석)와 콩 (품종명:황금콩) 및 감나무 품종명:부유)를 공시작물로 하여, 수원 (매산로 2가) 농가 포장에서, 2013년 폭염기인 6월 16일과 8월 19일 2회 에 걸쳐 약 $30 \sim 90$ 분 간격으로 24 시간동안 열적외선 표면온 도측정기 $\left(\mathrm{SK}-8700 \mathrm{II}\right.$ : 오차범위 $0.5^{\circ} \mathrm{C}$ )를 이용하여 직사광 선을 받지 않는 작물잎 표면온도를 측정하여 2 회 측정치의 평균값을 근거로 하여 작물잎 표면온도의 일중변화양상을 분석하였다.

본 연구에서, 하루의 시각을 자정을 기준으로 하여 기준 일 자정으로부터 다음일 자정까지의 24 시간에 대하여 기준 일 자정을 0 으로 하여 그로부터 경과된 시간을 분 단위로 나타내어 「E\&E time」이라 명명하고, 하루 24시간인 1,440 분을 $\ulcorner\mathrm{Kmin}$. 또는 $\mathrm{K}$ 분」이라고 명명한 단위로 표시한 시각 에 따라 시각 $(\mathrm{Kmin}$.)별 작물체 잎 표면온도의 변화양상을 분석하였다.

작물체 잎 표면온도의 일중변화 양상을 추정하기 위한 모형은 식 (1)과 같은 $\sin$ 함수의 형태로 개발하였다.

$$
\mathrm{T}=\mathrm{a} \cdot \sin [\mathrm{b} \cdot(\mathrm{x}+\mathrm{c})]+\mathrm{d}
$$

단, T는 잎 표면온도 $\left({ }^{\circ} \mathrm{C}\right), \mathrm{x}$ 는 $\mathrm{E} \& \mathrm{E}$ time (Kmin.), a, b, c, d는 계수임.

상기 모형의 계수는 다음과 같이 설정하였다. $a$ 값은 일중 변화 진폭의 $1 / 2$ 에 해당하는 값을 뜻하는 계수이므로 실측 한 최고온도와 최저온도 차이의 $1 / 2$ 값으로 설정하였으며, $b$ 값은 주기를 뜻하는 계수이므로 하루를 1주기로 하였기에 1.0 을 적용하였다. c값은 $\sin$ 함수 graph의 기준시각과 관련 된 계수이므로 실측치의 graph형태 (Fig. 1)에 근거하여 자 정시각이 0이 되도록 graph를 $\mathrm{x}$ 축 방향으로 평행이동 시키 는 값을 적용하였다. $d$ 값은 최고온도와 최저온도의 평균치 가 graph의 중심에 오면서 실측치가 $\mathrm{y}$ 축에 표현될 수 있도 록 graph를 y축 방향으로 평행이동 시키는 값을 적용하였다.

본 연구는, 작물체 잎 표면온도의 일중변화양상을 폭염 기에 조사한 결과이므로 측정시기가 다른 일시의 온도를 추 정할 경우 그 온도 (T)의 절대값이 다르기 때문에 이 차이를 극복하기 위하여 상대적인 온도값으로 변환시킨 변수 $\left(\mathrm{T}^{*}\right)$, 즉 scale fector를 식 (2)와 같이 설정하여 작물별 잎 표면온 도의 일중변화 양상을 분석하였다.

$$
\mathrm{T}^{*}=(\mathrm{Tx}-\mathrm{Tn}) /(\mathrm{Tm}-\mathrm{Tn})
$$



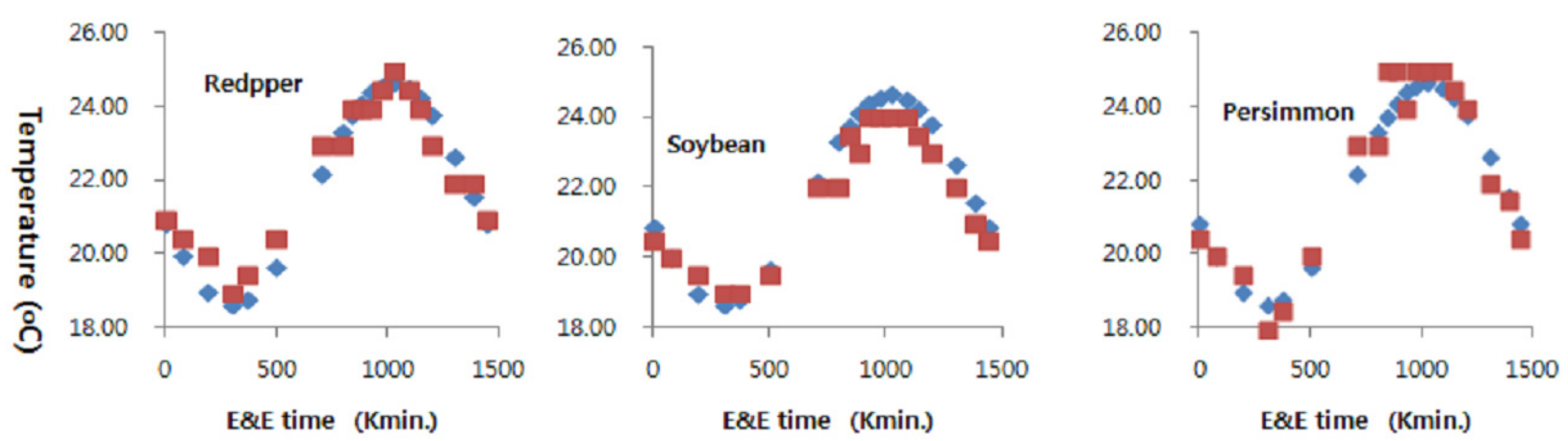

Fig. 1. Changes in the measured and estimated leaf surface temperature according to the E\&E time.

단, Tx (Daily leaf temperature : ${ }^{\circ} \mathrm{C}$ )는 일중시각별 잎 표면온도, Tn (Daily minimum leaf temperature : ${ }^{\circ} \mathrm{C}$ )은 일 중최저 잎 표면온도, Tm (Daily maximum leaf temperature : $\left.{ }^{\circ} \mathrm{C}\right)$ 은 일중최고 잎 표면온도 임.

또한, 작물 또는 처리 등이 다른 경우의 변화양상에 대한 상호 비교분석을 위한 지표로서 식 (3)과 같은 상대정밀도 (Relative sensitivity : RS)를 산출하여 작물별 같은 정밀도 를 얻기 위해 요구되는 측정 반복수를 산정하였다. 실측치 $(\mathrm{X})$ 에 대한 추정치 $(\mathrm{E})$ 의 상대정밀도 즉, $\mathrm{RS}(\mathrm{E} / \mathrm{X})$ 는 다음과 같이 산정된다.

$$
\mathrm{RS}(\mathrm{E} / \mathrm{X})=\left[\mathrm{S}\left(\mathrm{T}_{\mathrm{X}}\right) / \mathrm{S}\left(\mathrm{T}_{\mathrm{E}}\right)\right]=\mathrm{h}
$$

단, $\mathrm{S}\left(\mathrm{T}_{\mathrm{X}}\right)$ 는 실측치의 표준편차, $\mathrm{S}\left(\mathrm{T}_{\mathrm{E}}\right)$ 는 추정치의 표준 편차 임.

여기서 추정치와 실측치의 함수관계를 적용시키면 식 (3) 은 식 (4)와 같이 된다.

$$
\mathrm{RS}(\mathrm{E} / \mathrm{X})=[|\mathrm{dE} / \mathrm{dX}|] /\left(\mathrm{S}_{\mathrm{E}} / \mathrm{S}_{\mathrm{X}}\right)
$$

또한, 상기 식 (4)에서 추정치와 실측치의 표준편차 $\left(\mathrm{S}_{\mathrm{E}}\right.$ 및 $\mathrm{S}_{\mathrm{x}}$ )가 동일하다고 가정하면 식 (4)는 식 (5)와 같이 된다. 즉,

$\mathrm{RS}(\mathrm{E} / \mathrm{X})=\left[\mathrm{S}\left(\mathrm{T}_{\mathrm{X}}\right) / \mathrm{S}\left(\mathrm{T}_{\mathrm{E}}\right)\right]=|\mathrm{dE} / \mathrm{dX}|=\mathrm{h}$

그리고, 실측치 $(\mathrm{X})$ 와 추정치 $(\mathrm{E})$ 의 분산 (Variance : V) 의 비율은 식 (6)과 같이 된다.

$$
\left[\mathrm{V}\left(\mathrm{T}_{\mathrm{X}}\right) / \mathrm{V}\left(\mathrm{T}_{\mathrm{E}}\right)\right]=\left[\mathrm{S}^{2}\left(\mathrm{~T}_{\mathrm{X}}\right) / \mathrm{S}^{2}\left(\mathrm{~T}_{\mathrm{E}}\right)\right]=\mathrm{h}^{2}
$$

따라서,

$$
\mathrm{V}\left(\mathrm{T}_{\mathrm{X}}\right)=\mathrm{h}^{2} \cdot \mathrm{V}\left(\mathrm{T}_{\mathrm{E}}\right)
$$

여기서 $\mathrm{h}^{2}$ 이 뜻하는 것은, 실측치가 추정치의 정밀도와 같은 정밀도를 갖기 위하여 필요한 상대적 반복치를 의미하
게 된다 (Mandel, 1964 : Eom et al.,1988).

\section{Results and Discussion}

작물 잎 표면온도의 시간적 변화는 태양 일사, 풍속, 증 발산 및 잎의 각도 등에 따라 달라지게 되며, 이들 요소들은 일중 시간에 따라 상승과 하강의 변화를 보이며 태양 일사 가 많을수록 또한 잎의 각도가 태양광과 수직 방향일수록 작물 잎 표면 온도는 상승하게 될 것이며, 반면 증발산과 풍 속이 클수록 잎 표면 온도는 하강하게 될 것이나, 이들 요소 들은 동시에 복합적으로 작용하므로, 어느 한 요소가 잎 표 면 온도 변화에 어느만큼 영향을 미쳤는지를 구명하기란 매 우 어려운 문제이다. 따라서 본 연구에서는 이들 요소들의 복합적인 영향의 결과로 나타나는 일중 시각별 작물 잎 표 면 온도를 예측하고자 하였다.

작물 잎 표면온도의 일중 변화양상 (Fig. 1)을 보면, 일중 최고온도 및 최저온도를 나타내는 시각은 각각 $1,020 \mathrm{~K}$ 분

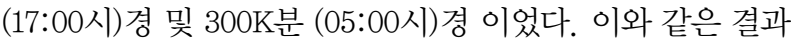
는 $5 \mathrm{~cm}$ 깊이 토양온도의 경우 일중 최고온도 및 최저온도를 나타내는 시각 (Eom et al., 1990)과 비교 해 볼 때 약 30분 정도 이른 시각이었다.

실측한 작물체 잎 표면온도의 일중변화는 3작물 모두 하 루 24시간(1,440 Kmin.)을 1주기로 하는 $\sin$ 함수 형태를 보 였다. 따라서 식 (1)의 모형에서 $\mathrm{b}$ 값은 1.0 을 적용하였다. 또 한 자정 $(\mathrm{Kmin} .=0)$ 의 시각을 $\mathrm{x}$ 축의 0 값으로 맞추기 위하여 $\sin$ 함수 graph를 $\mathrm{x}$ 축 방향으로 평행이동 시키기 위한 계수 c값은 780 을 적용하였다. 또한 graph진폭의 $1 / 2$ 값인 a값은 고추와 콩 및 감나무 잎의 경우 각각 3.0 과 2.5 및 3.5 이었 으며 그 평균인 3.0 을 적용하였다. 그리고 graph의 y축 방 향 평행이동 관련 계수인 $\mathrm{d}$ 는 고추와 콩 및 감나무 잎의 경 우 각각 22.0 과 21.5 및 21.5 이었으며 그 평균인 21.67 을 적용하여, 결론적으로 본 연구에서 폭염기 작물체 잎 표면 온도의 일중변화 추정모형을 식 8)과 같이 설정 하였다.

$$
\mathrm{T}_{\mathrm{E}}=3.0 \cdot \sin (\mathrm{X}+780)+21.67
$$

단, $\mathrm{T}_{\mathrm{E}}$ 는 시각별 추정 잎 표면온도, $\mathrm{X}$ 는 $\mathrm{E \& E}$ time (Kmin.) 임.

식 (8)의 모형에 의한 시각별 추정온도 $\left(\mathrm{T}_{\mathrm{E}}\right)$ 와 실측온도 
Table 1. Deviation between the measured temperature and estimated temperature.

\begin{tabular}{|c|c|c|c|c|c|c|c|c|}
\hline \multirow{2}{*}{$\begin{array}{l}\text { E\&E time } \\
\text { (Kmin.) }\end{array}$} & \multicolumn{3}{|c|}{ Measured Temperature $\left({ }^{\circ} \mathrm{C}\right)<\mathrm{A}>$} & \multirow{2}{*}{$\begin{array}{c}\text { Estimated } \\
\text { Temperature }\left({ }^{\circ} \mathrm{C}\right) \\
<\mathrm{B}>\end{array}$} & \multicolumn{4}{|c|}{ Deviation $(|\mathrm{A}-\mathrm{B}|)\left({ }^{\circ} \mathrm{C}\right)$} \\
\hline & $\begin{array}{c}\text { Red } \\
\text { pepper }\end{array}$ & $\begin{array}{l}\text { Soy } \\
\text { bean }\end{array}$ & $\begin{array}{l}\text { Persi- } \\
\text { mmon }\end{array}$ & & $\begin{array}{c}\text { Red } \\
\text { pepper }\end{array}$ & $\begin{array}{l}\text { Soy } \\
\text { bean }\end{array}$ & $\begin{array}{l}\text { Persi- } \\
\text { mmon }\end{array}$ & Mean \\
\hline 0 & 21.0 & 20.5 & 20.5 & 20.89 & 0.106 & 0.394 & 0.394 & 0.298 \\
\hline 75 & 20.5 & 20.0 & 20.0 & 20.00 & 0.497 & 0.003 & 0.003 & 0.168 \\
\hline 190 & 20.0 & 19.5 & 19.5 & 19.01 & 0.991 & 0.491 & 0.491 & 0.658 \\
\hline 300 & 19.0 & 19.0 & 18.0 & 18.67 & 0.330 & 0.330 & 0.670 & 0.443 \\
\hline 370 & 19.5 & 19.0 & 18.5 & 18.81 & 0.691 & 0.191 & 0.309 & 0.397 \\
\hline 495 & 20.5 & 19.5 & 20.0 & 19.69 & 0.808 & 0.192 & 0.308 & 0.436 \\
\hline 700 & 23.0 & 22.0 & 23.0 & 22.19 & 0.809 & 0.191 & 0.809 & 0.603 \\
\hline 795 & 23.0 & 22.0 & 23.0 & 23.34 & 0.337 & 1.337 & 0.337 & 0.670 \\
\hline 840 & 24.0 & 23.5 & 25.0 & 23.79 & 0.209 & 0.291 & 1.209 & 0.570 \\
\hline 880 & 24.0 & 23.0 & 25.0 & 24.13 & 0.127 & 1.127 & 0.873 & 0.709 \\
\hline 925 & 24.0 & 24.0 & 24.0 & 24.42 & 0.416 & 0.416 & 0.416 & 0.416 \\
\hline 970 & 24.5 & 24.0 & 25.0 & 24.60 & 0.099 & 0.599 & 0.401 & 0.366 \\
\hline 1020 & 25.0 & 24.0 & 25.0 & 24.67 & 0.330 & 0.670 & 0.330 & 0.443 \\
\hline 1090 & 24.5 & 24.0 & 25.0 & 24.53 & 0.031 & 0.531 & 0.469 & 0.344 \\
\hline 1140 & 24.0 & 23.5 & 24.5 & 24.27 & 0.268 & 0.768 & 0.232 & 0.423 \\
\hline 1195 & 23.0 & 23.0 & 24.0 & 23.84 & 0.837 & 0.837 & 0.163 & 0.612 \\
\hline 1300 & 22.0 & 22.0 & 22.0 & 22.70 & 0.696 & 0.696 & 0.696 & 0.696 \\
\hline 1385 & 22.0 & 21.0 & 21.5 & 21.60 & 0.396 & 0.604 & 0.104 & 0.368 \\
\hline 1440 & 21.0 & 20.5 & 20.5 & 20.89 & 0.107 & 0.393 & 0.393 & 0.298 \\
\hline Average & 22.34 & 21.79 & 22.32 & 22.21 & 0.425 & 0.530 & 0.453 & 0.469 \\
\hline
\end{tabular}

$(\mathrm{Tx})$ 와의 편차 (Table 1)의 일평균편차는 고추와 콩 및 감나 무의 경우 각각 0.425 와 0.530 및 0.453 도 이었으며, 전체 에 대한 평균편차는 0.469 도 이었다.

또한 식 8의 모형에 의한 추정치와 실측치와의 상관을 보면 (Fig. 2), 고추와 콩 및 감나무 잎의 경우 결정계수 $\left(\mathrm{R}^{2}\right)$ 가 각각 0.96 과 0.97 및 0.96 을 나타내어 3 작물의 경우 모두 $1 \%$ 유의수준에서 유의성 있는 고도의 상관관계를 보였다. 본 연구에서 작물체 잎 표면온도는 연중 폭염기에 측정 된 값이었으며, 다른 시기의 작물체 잎 표면온도는 이와 차 이가 클 것이나, 온도의 일중변화를 나타내는 graph의 형태 는 같을 것이라고 사료된다. (Eom et al., 1990). 따라서 이 와 같은 조사시기별 차이에 의한 온도 절대값의 차이를 극 복하며 동일한 변화형태를 추정할 수 있는 모형개발을 위하 여, 온도를 절대치 (T)가 아닌 식 (9)에 의한 상대치로 변환 (Scale fector)시킨 값 $\left(\mathrm{T}^{*} \mathrm{x}\right)$ 을 측정대상 변수로 삼아 모형을 설정하고자 하였다.

$$
\mathrm{T}^{*} \mathrm{x}=(\mathrm{Tx}-\mathrm{Tn}) /(\mathrm{Tm}-\mathrm{Tn})
$$

단, $\mathrm{Tx}$ 는 일중시각별 잎 표면온도, $\mathrm{Tn}$ 은 일중최저 잎 표 면온도, $\mathrm{Tm}$ 은 일중최고 잎 표면온도 임.

식 (9)와 같은 scale factor를 이용하여 설정되는 모형에 서 변환된 변수 $\mathrm{T}^{*} \mathrm{x}$ 의 값은 $0 \sim 1.0$ 의 값을 가지게 되므로

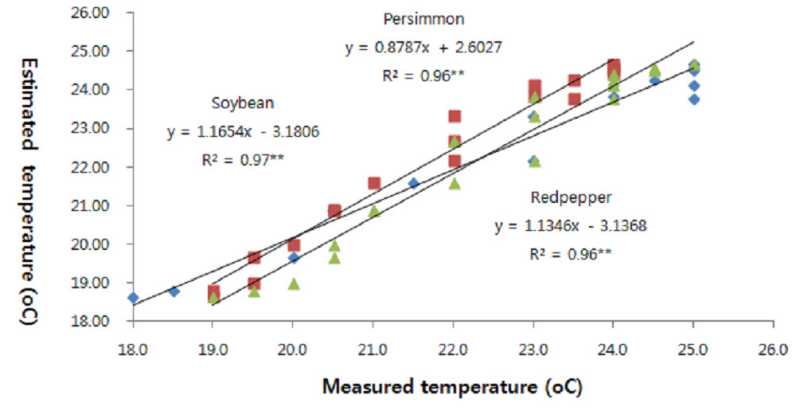

Fig. 2. Relationship between the measured and estimated leaf surface temperature.

$\mathrm{a}$ 값은 0.5 로 설정 하였으며, 하루가 1 주기로 변화하므로 b 값은 1.0 으로 설정되었다. 또한 c값은 식 (8)의 모형과 같이 780 으로 설정하였으며, $\mathrm{d}$ 값은 graph진폭의 $1 / 2$ 인 0.5 로 설 정하였다. 따라서 본 연구에서 scale factor를 이용한 작물 체 잎 표면온도의 일중변화 추정치 $\left(\mathrm{T}^{*} \mathrm{e}\right)$ 모형은 식 (10)과 같 이 설정하였다.

$\mathrm{T}^{*} \mathrm{e}=0.5 \cdot \sin (\mathrm{X}+780)+0.5$

단, X는 E\&E time (Kmin.) 임.

상기 식 (10)의 모형에 의한 일중시각별 작물 잎 표면온도 


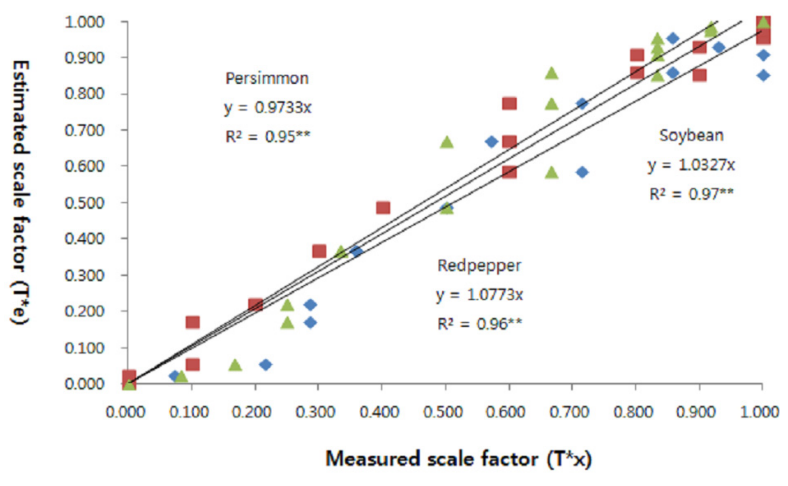

Fig. 3. Relationship between the measured and estimated scale factor for the leaf surface temperature.

의 추정치 $\left(\mathrm{T}^{*} \mathrm{e}\right)$ 와 식 $(9)$ 에 의한 변환된 실측치 $\left(\mathrm{T}^{*} \mathrm{x}\right)$ 와의 상 관관계는 (Fig. 3) 3작물 모두 결정계수 $\left(R^{2}\right)$ 가 0.95이상으 로 $1 \%$ 유의수준에서 유의성 있는 고도의 상관관계를 보였다.

상기 식 (10)의 모형은 낮 시간 동안 작물 잎의 일중 수광 상태가 일정한 조건 즉, 직사광선을 받지 않는 환경 조건 등 에서 대부분 작물(곡류, 과채류, 과수)의 잎 표면 온도 예측 에 적용 될 수 있을 것으로 판단된다.

본 연구에서 설정된 모형 (식 (10)에 의한 추정치 $\left(\mathrm{T}^{*} \mathrm{e}\right)$ 의 실측치 $\left(\mathrm{T}^{*} \mathrm{x}\right)$ 에 대한 상대정밀도인 $\mathrm{RS}\left(\mathrm{T}^{*} \mathrm{e} / \mathrm{T}^{*} \mathrm{x}\right)$ 의 값은 (Fig. 3), 고추와 콩 및 감나무 잎의 경우 각각 1.078 과 1.033 및 0.973 이었으며, 이를 근거로 하여 산정된 100반 복치의 추정치와 동일한 상대정밀도를 얻기 위하여 요구되 는 실측치 반복수는 고추와 콩 및 감나무 잎의 경우 각각 116 과 107 및 95 이었다.

\section{Conclusions}

고추와 콩 및 감나무 잎을 대상으로 하여 연중 최고온도 를 나타내는 폭염기에 2 회에 걸쳐 약 30 분 90 분 간격으로 24 시간동안 작물체 잎 표면온도를 측정한 결과를 이용하여, 작물 잎 표면온도의 일중변화 추정 모형을 개발한 결과는 다음과 같다.

1. 하루의 시각을 자정을 기준으로 하여 기준일 자정으 로부터 다음일 자정까지의 24 시간에 대하여 기준일 자정을 0 으로 하여 그로부터 경과된 시간을 분단위로 나타내어 $\ulcorner\mathrm{E} \& \mathrm{E}$ time」이라 명명하고, 하루 25시간인 1,440 분을 $「 \mathrm{Kmin}$. 또는 $\mathrm{K}$ 분」이라고 명명한 단위로 표시한 시각을 독립변수 (X : rad단위)로 하여 시각 (Kmin.)별 작물체 잎 표면온도를 추정할 수 있는 모형 을 식 (1)의 삼각함수 형태로 개발 하였다.

$$
\mathrm{T}=\mathrm{a} \cdot \sin [\mathrm{b} \cdot(\mathrm{X}+\mathrm{c})]+\mathrm{d}
$$

단, T는 잎 표면온도 (도), X는 $\mathrm{E \& E}$ time (Kmin.), $\mathrm{a}, \mathrm{b}, \mathrm{c}, \mathrm{d}$ 는 계수임.

2. 작물체 잎 표면의 일중최고온도 및 최저온도를 나타

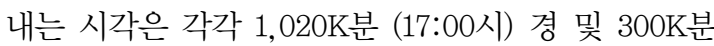

(05:00시) 경 이었다.

3. 고추와 콩 및 감나무 잎 표면온도의 평균치를 이용하 여 설정된 작물체 잎 표면온도의 폭염기 일중시각별 온도 추정모형은 식 (2)와 같다.

$\mathrm{T}=3.0 \cdot \sin (\mathrm{X}+780)+21.67$

단, T와 X는 식 (1)과 동일함.

4. 상기의 산정된 계수들을 이용하여 폭염기의 추정한 잎 표면온도와 3 가지 작물체 잎의 실측한 잎 표면온 도와는 3작물 경우 모두 고도의 유의성이 있었으며 $\left(\mathrm{R}^{2}>0.96\right)$, 실측치와 추정치간의 전체 평균편차는 0.469 도 이었으며, 폭염기 작물체 잎 표면온도의 일 중변화에 대한 실측치와 추정치간의 평균편차는 일중 시각 및 표면온도와는 상관이 없었다.

5. 계절별 일중온도의 절대값 차이를 극복하기 위하여 실제온도 (T)를 식 (3)과 같이 변환시킨 변수 ( $\left.\mathrm{T}^{*}\right)$ 에 대 한 일중변화 양상의 실측치 $\left(\mathrm{T}^{*} \mathrm{x}\right)$ 와 식 (4)에 의한 추 정치 $\left(\mathrm{T}^{*} \mathrm{e}\right)$ 간에는 3 작물 경우 모두 고도의 유의성이 있었으며 $\left(\mathrm{R}^{2}>0.95\right)$, 본 연구에서 식 (4)를 작물체 잎 표면온도의 일중변화 양상 추정 모형으로 설정 하였다.

$\mathrm{T}^{*}=(\mathrm{Tx}-\mathrm{Tn}) /(\mathrm{Tm}-\mathrm{Tn})$

단, Tx는 일중시각별 잎 표면온도, $\mathrm{Tn}$ 은 일중최저 잎 표면온도, $\mathrm{Tm}$ 은 일중최고 잎 표면온도 임.

$\mathrm{T}^{*} \mathrm{e}=0.5 \cdot \sin [(\mathrm{X}+780)]+0.5$

단, X는 E\&E time (Kmin.) 임.

6. 일중시각에 따른 고추, 콩 및 감나무 잎 표면온도의 실측치에 대한 추정치의 상대정밀도 (Relative sensitivity)는 각각 $1.078,1.033$ 및 0.973 으로써, 100 반 복치에 의한 추정치와 동일한 상대정밀도를 얻기 위 하여 요구되는 실측치 반복수는 각각 116, 107 및 95 이었다.

\section{References}

Eom, K.C., K.S. Ryu, and K.T. Um. 1988. Comparison of the measurement methods of soil water content. Korean J. Soil Sci. \& Fert. 21:367-372.

Eom, K.C., E.R. Son, and K.S. Ryu. 1990. Changes in evapotranspiration and soil water status to vinyl mulching. Korean J. Soil Sci. \& Fert. 21:367-372.

Eom, K.C., K.C. Song, K.S. Ryu, Y.K. Sonn, and S.E. Lee. 1995. Model equations to estimate the soil water characteristics curve using scaling factor. Korean J. Soil Sci. \& Fert. 28:227-232.

Eom, K.C. and K.R. Eom. 2008. Mathematics for agricultural sciences. Daewon Publishers, Korea, Seoul. 438-491 (In Korean). 
Hillel, D. and D.E. Erick. 1990. Scaling in soil physics : Principles and applications. Soil Science Society of America, Inc. Madison, Wisconsin, USA. 300-318.

Mandel,J. 1964. The statistical analysis of experimental data. John Wiley \& Sons, New York, 58-77, 363-389.

Miller, E.E. and R.D. Miller. 1955a. Theory of capillary flow : I. Practical implications. Soil Sci. Soc. Am. Proc. 19:267-271.

Miller, E.E. and R.D. Miller. 1955b. Theory of capillary flow : II.
Experimental information. Soil Sci. Soc. Am. Proc. 19:271 -275 .

Lal, R. and Shukla M. 2004. principles of soil physics. Marcel Dekker, Inc. USA. 515-555.

Patricia, M.T. and D.R. Nielsen. 1984. Scale factors in soil science. Soil Sci. Soc. Am. J. 48:953-959

Scott, H.D. 2000. Soil physics agricultural and environmental applications. Iowa State University Press. Ames. IA. 